\title{
Some aspects of surgical hemostasis of massive postpartum hemorrhage
}

\author{
Serik Iskakov $^{1}$, Bahit Malgazhdarova ${ }^{1}$, Bahit Saurbaeva ${ }^{1}$, Aisulu Tulemisova ${ }^{1}$, Marat Yermuratov ${ }^{1}$
}

${ }^{1}$ Department of Obstetrics and Gynecology №2, JSC "Medical University Astana", Astana, Kazakhstan

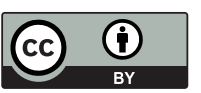

This work is licensed under a Creative Commons Attribution 4.0 International License

\begin{abstract}
J CLIN MED KAZ 2017; 3(45 SUPPL 3):63-66 Автор для корреспонденции:Малгаждарова Бахыт Сексенбаевна, кафедра акушерства и гинекологии №2 АО «Медицинский университет Астана», Адрес: 010000 Казахстан, г.Астана, ул. Манаса, 22 Тел.:+77051000049. Дом. Телефон 87172222839 e-mail:baist_m@mail.ru
\end{abstract}

\begin{abstract}
Objective: to study the effectiveness of compression sutures in massive postpartum obstetric hemorrhages.

Methods: The study involved 5370 pregnant women who delivered babies in the Akmola Regional Hospital No. 2 in 2015-2017. Clinical, laboratory and instrumental methods were used in the study. A retrospective analysis of cases of obstetric hemorrhages was carried out in 2006 - 2008, before the introduction of haemostatic sutures to the uterus in cases of Massive Obstetric Hemorrhage (MOH).
\end{abstract}

Results: Before the introduction of haemostatic sutures to the uterus, in the cases of $\mathrm{MOH}$, hysterectomy was mainly performed, with the expanded volume prevailing, i.e., the extirpation of the uterus, which was $6.1 \%$ of the total number of obstetric hemorrhages, and $35.7 \%$ from the $\mathrm{MOH}$. During the last 3 years (2015-2017) in the maternity ward of Akmola Regional Hospital \# 2, the frequency of obstetric hemorrhage decreased from $4.1 \%$ to $2.3 \%$ (1.8 times) compared to the period before the application of haemostatic sutures to the uterus. An attitude towards the removal of the uterus was changed qualitatively. With the introduction of the clinical protocol "Obstetric Bleeding" and the development of the technique of haemostatic sutures on the uterus, with obstetric hemorrhages in the maternity ward, hysterectomy was reduced by 2 times.

Conclusions: timely and technically correctly applied haemostatic sutures to the uterus are effective methods that allow to save the organ and reproductive function of women who underwent massive obstetric hemorrhage.

Keywords: cesarean section - postpartum hemorrhage - surgical hemostasis - haemostatic sutures to the uterus - hysterectomy

\section{ТҰЖЫРЫМДАМА}

\section{БОСАНҒАННАН КЕЙІН МАССИВТІ ҚАН КЕТУДЕГІ ОТАЛЫҚ ҚАН ТОҚТАТУДЫН КЕЙБІР МӘСЕЛЕЛЕРІ}

Искаков С.С. ${ }^{1}$, Малгаждарова Б.С. ${ }^{1}$, Саурбаева Б. Ж. ${ }^{1}$, Тулемисова А. А. ${ }^{1}$, Ермуратов М. Ә. ${ }^{1}$

${ }^{1} № 2$ акушерия және гинекологии кафедрасы, АҚ «Астана медицина университеті», Астана қаласы,Қазақстан

Мақсаты: Босанғаннан кейін кезенде әйелдерде массивті қан кетудегі компрессиондық тігістің тиімділігін зерттеу.

Зерттеудің әдістері: Зерттеуге 5370 жүкті әйелдер қатысты. Олар Ақмола областық №. 2 ауруханасында (АОА) $2015-2017$ жылдары босанғандар. Клиникалық, лабораториялық және құрал жабдықтар қолдану әдістерімен зерттелген. Ретроспективтік талдау $2006-2008$ жылдары болған акушерлік массивті қан кету (АМҚК) жағдайларын жатырға гемостатикалық тігістерді енгізгенге дейін жасалды.

Нәтижелері: Жатырға гемостатикалық тігіс салу тәжірибеге енгізілгенше дейін, АМқК жағдайларында негізінен жатырды алып тастау(гистерэктомия), соның ішінде толық көлемде алып тастау(экстирпация) 6,1\% жалпы акушерлік қан кетудуде, ал АМқК-де 35,7\% құрады. Ақырғы 3 жылда (2015-2017ж.) жатырға гемостатикалық тігіс салғанға дейінгі кезенмен салыстырғанда №. 2 АОА босандыру бөлімшесінде акушерлік қан кету 4,1\% дан 2,3\% ға 1,8 есеге төмендеді. Жатырды алып тастау мәселесіне сапалық жағынан көзқарас өзгерді. «Акушерлік қан кету» клиникалық протоколы енгізілуі, жатырға гемостатикалық тігіс салу техникасын игерілуі, босандыру бөлімшесінде акушерлік қан кетуде жатырды алып тастауды 2 есеге төмендетті.

Қортынды: уақытылы жәнежатырға гемостатикалық тігіс салу техникасы дұрыс істелінсе, ол өте тыйымды, әйел ағзасын, кейін репродуктивтік қызыметіңАМқК-де сақтауға мүмкіндік беретін, әдіс болып табылады.

Маңызды сөздер: кесар тілігі - босанғаннан кейін қан кету - оталық гемостаз - жатырға гемостатикалық тігістер - жатырды алып тастау(гистерэктомия) 
PEЗЮME

НЕКОТОРЫЕ АСПЕКТЫ ХИРУРГИЧЕСКОГО ГЕМОСТАЗА МАССИВНОГО ПОСЛЕРОДОВОГО КРОВОТЕЧЕНИЯ Искаков С.С. ${ }^{1}$ Малгаждарова Б.С. ${ }^{,}$Саурбаева Б.Ж. ${ }^{1}$,Тулемисова А.А. ${ }^{1}$, Ермуратов М. А. ${ }^{1}$

${ }^{1}$ Кафедра акушерства и гинекологии №2, АО «Медицинский университет Астана», г.Астана

Цель исследования: изучить эффрективности компрессионных швов при массивных акушерских кровотечениях(МАК).

Методы. В исследовании приняли участие 5370 беременные, родоразрешенные в Акмолинской областнойбольнице (АОБ) №2 в 2015-2017гг. Использовались клинические, лабораторные, инструментальные методы. Проведен ретроспективный анализ случаев акушерских кровотечений с 2006 по 2008 годы, до внедрения гемостатических швов на матку в случаях МАК.

Результаты. До внедрения гемостатических швов на матку, в случаях МАК, в основном, производилась гистерэктомия, причем расширенный объем был превалирующим, то есть экстирпация матки, что составил 6,1\% из общего числа акушерских кровотечений, а из МАК- 35,7\%. За последние 3 года(2015-2017гг) в родильном отделений АОБ №2 частота акушерских кровотечении снизилась от 4,1\% до 2,3\% (в 1,8 раза) по сравнению с периодом до применения гемостатических швов на матку. Качественно изменилось отношение к удалению органа - матке. С внедрением клинического протокола «Акушерские кровотечения» и освоением техники гемостатических швов на матку, при акушерских кровотечениях в родильном отделении, гистерэктомия снижена в 2 раза.

Выводы: своевременно проведенные и технически правильно наложенные гемостатические швы на матку являются эффрективными методами, позволяющие сохранить орган и последующим репродуктивную функцию у женщин перенесших МАК.

Ключевые слова: кесарево сечение - послеродовое кровотечение - хирургический гемостаз - гемостатические швы на матку - гистерэктомия

\section{Введение}

Акушерские кровотечения всегда были и являются одной из основных проблем для акушерства.Послеродовое кровотечение (ПРК) остается до сих пор одной из основных причин материнской заболеваемости и смертности во всем мире. Успех в «управлении» и остановке ПРК определятся их выявлением и лечением на ранней стадии $\{1\}$.По данным В.И. Кулакова и соавт. (2000 г.), анализ 156 наблюдений массивных кровотечений показал, что причинами были: преждевременная отслойка плаценты (ПОНРП) - 30\%, предлежание плаценты (ПП) - 20\%, патология последового периода $-18 \%$, гипо - и атония матки - 27\%, после кесарева сечения $-2 \%$, разрыв матки $-2 \%$. Кроме того наследственные и приобретенные дефекты системы гемостаза были причинами кровотечения в $1 \%\{2\}$.Консервативное лечение массивного акушерского кровотечения(МАК), как тазовая артериальная эмболизация, поэтапная, ступенчатая деваскуляризация матки и / или лигирование подчревной артерии, стало надежной и эффективной альтернативой гистерэктомии $\{3\}$.Хотя дальнейшие долгосрочные и последующие исследования все же необходимы, но эти процедуры, по мнению зарубежных исследователей, не ухудшают последующую рождаемость и исходы беременности $\{4\}$.

Цель исследования - оценка эффективности компрессионных швов примассивных акушерских кровотечениях(МАК).

\section{Материалы и методы исследования}

Материалом явились госпитализированные беременные, роженицы в 2015-2017гг. с близлежащего района Акмолинской области, родоразрешенные и выписанные из послеродового отделения Акмолинской областной больнице №2.Методы исследования: клинические, лабораторные (анализы крови, включая биохимические и гемостазиограмму при необходимости, анализ мочи), инструментальные: флюрография и ультразвуковое исследование плода, при необходимости компьютерная томография органов брюшной полости. Для сравнения проведен ретроспективный анализ случаев акушерских кровотечений с 2006 по 2008 годы, до внедрения гемостатических швов на матку в случаях МАК. При МАК последовательно применялся метод гемостатических швов на матку по О*Лири и Б-Линча.

\section{Результаты исследования и обсуждения.}

Как видно из таблицы №1, частота акушерских кровотечений составила от 1,6 до $5,1 \%$. Основной причиной кровотечения была атония матки, частота которой составила в 2006 году до 81,6\% среди кровотечений. При МАК в 2008 году в 75\% произведено удаление матки в виде надвлагалищной ампутации и экстирпации с маточными трубами. В 2007 году, при МАК, произведена гистерэктомия, что составило 66,7\%. Экстирпация матки в двух случаях проведена без придатков, а в одном случае с правыми придатками и левой трубой. Кровопотери в эти годы всегда были свыше 2000,0 мл. Кроме того в 2007 году была произведена перевязка подвздошных артерии при кровопотери 1500,0 мл, с оставлением матки при диагностированной матке Кювелера, на фоне частичной ПОНРП в доношенном сроке беременности.

Таким образом, до внедрения гемостатических швов на матку, в случаях МАК в основном заканчивались путем гистерэктомии, причем расширенный объем был превалирующим, то есть экстирпация матки за период исследования произведена в 5 случаях, что составило $6,1 \%$ из общего числа акушерских кровотечении, а из МАК$35,7 \%$.

Таблица 1 Данные об акушерских кровотечениях за 2006-2008гг.

\begin{tabular}{|c|c|c|c|c|c|c|}
\hline Нозология & 2006 & $\%$ & 2007 & $\%$ & 2008 & $\%$ \\
\hline Роды & \multicolumn{2}{|c|}{955} & \multicolumn{2}{|c|}{976} & \multicolumn{2}{|c|}{1023} \\
\hline Кесарево сечение & 156 & 16,3 & 156 & 15,9 & 160 & 15,6 \\
\hline \multicolumn{7}{|l|}{ Акушерские кровотечения } \\
\hline Из них: & 49 & 5,1 & 17 & 1,7 & 16 & 1,6 \\
\hline $\begin{array}{l}\text { Преждевременная отслойка нормально расположен- } \\
\text { ной плаценты }\end{array}$ & 7 & 14,3 & 9 & 52,9 & 7 & 43,8 \\
\hline Предлежание плаценты & 2 & 4,1 & 2 & 11,8 & 2 & 12,5 \\
\hline
\end{tabular}




\begin{tabular}{|c|c|c|c|c|c|c|}
\hline Атония матки & 40 & 81,6 & 6 & 35,3 & 7 & 43.8 \\
\hline Массивные акушерские кровотечения свыше 1 литра & 4 & 8,2 & 6 & 35,3 & 4 & 25,0 \\
\hline Гистерэктомия & $\begin{array}{c}1: \\
\text { Экстир пация - } 1\end{array}$ & 2,0 & $\begin{array}{l}\text { 4: } \\
\text { Надвлага-лищная ампу- } \\
\text { тация матки - } 1 \text { Экстир } \\
\text { пация - } 3\end{array}$ & 23,5 & $\begin{array}{l}\text { 3: Надвлага лищная- } \\
\text { ампутация матки - } 2 \\
\text { Экстир пация - } 1\end{array}$ & 18,8 \\
\hline
\end{tabular}

Таблица 2 Основные показатели за 2014-2016 годы

\begin{tabular}{|c|c|c|c|c|c|c|}
\hline Нозология & $2015 \Gamma$ & & 2016год & & 2016год & \\
\hline Количество родов & 1618 & & 1793 & & 1959 & \\
\hline Физиологические роды & 1103 & 68,2 & 1215 & 67,7 & 1499 & 76,5 \\
\hline Кровотечений & & & & & & \\
\hline Всего,из них: & 30 & & 37 & 2,1 & 55 & 2,8 \\
\hline Предлежание плаценты & 5 & 16,7 & 2 & 5,4 & 7 & 12,7 \\
\hline Отслойка нормально расположенной & & & & & & \\
\hline Плаценты & 10 & 33,3 & 14 & 37,8 & 18 & 32,7 \\
\hline Послеродовые кровотечения & 10 & 33,3 & 13 & 35,1 & 18 & 32,7 \\
\hline Кровопотеря больше 1 литра & 5 & 16,7 & 8 & 21,6 & 12 & 21,8 \\
\hline Кесарева сечение & 261 & 16,1 & 305 & 16,8 & 384 & 19,6 \\
\hline Компрессионные швы после кесарева сечения & - & & 3 & 8,1 & 3 & 5,4 \\
\hline Компрессионные швы после родов & - & & 1 & 2,7 & - & \\
\hline Гистерэктомия & $\begin{array}{l}\text { 2: Экстирпация матки } \\
-1 \text { НАМ-1 }\end{array}$ & 6,6 & $\begin{array}{l}\text { 2: Экстирпация матки } \\
-1, \text { после Б-Линча. } \\
\text { НАМ-1 }\end{array}$ & 5,4 & $\begin{array}{l}\text { 3: Экстирпация матки } \\
\text {-2 НАМ-1 }\end{array}$ & 5,4 \\
\hline
\end{tabular}

Как видно из таблицы №2, частота акушерских кровотечении составила от 1,1 до $2,8 \%$. Основными причинами кровотечении были ПОНРП и ПРК. За исследуемый период (Згода) у7 и дополнительно у 2 в 2017 году в 1 полугодие, то есть9 родильницам проведены гемостатические швы в процессе родоразрешения, согласно клинического протокола «Акушерские кровотечения» М3 РК (№ 17 за 2016года): из них у 8 в процессе операции кесарева сечения и у одной после самопроизвольных повторных(2) срочных родов с рубцом на матке.

Обследованные были в возрасте 19 лет-1, 21 года- 2, 27 лет-2, 30 лет-1, 35 лет-1, 39 лет- 1, 40 лет-1. По паритету: первородящие - 4, повторнородящие - 5, в том числе двое многорожавшие(предстояли 5 и 6 роды).

Одним из основных факторов, увеличивающих частоту акушерских кровотечений считается увеличение процента абдоминального родоразрешения. Но в наших наблюдениях резкого увеличения частоты кесарева сечения не наблюдалось.

Показаниями для оперативного (экстреннего) родоразрешения путем кесарева сечения были:

1. В двух случаях - рубец на матке:

- при доношенном сроке беременности дородовое излитие вод(безводный промежуток - 3 часа 10 мин.) и неподготовленность родовых путей. Шейка матки по Бишоп - 6 баллов. В процессе кесарево сечения при возникшей атонии матки наложены О*Лири и Б-Линча. Кровопотеря составила 1500,0 мл.

- При недоношенном сроке 34 недель. Ножное предлежание. Полное предлежание плаценты. В процессе операции кесарева сечения при возникшей атонии матки наложены швы $\mathrm{O}^{*}$ Лири и Б-Линча. Кровопотеря составила 2000,0 мл.

2. В 5 случаях преждевременная отслойка нормально расположенной плаценты, сочеталась с антенатальной гибелью плода. Кровопотеря составила 1400,0-1500,0 мл.

3. В одном случае у первородящей диагностировандисстресс плода в первом периоде родов, при доношенном сроке беременности (39-40 недель), при дородовом излитии околоплодных вод(безводный промежуток -18 часов 00 минут). Крупные размеры плода. В процессе операции диагностирована атония матки. Наложены O*Лири и Б-Линча. Кровопотеря составила 1500,0 мл.

Клиническая картина при острых акушерских кровотечениях обусловлена потерей крови как объема циркулирующей крови,так и потерей компонентов крови. Снижение уровня гемоглобина (ниже $60-70$ г/л) возникает прикровопотере $\geq 40 \%$ ОЦК и вызывает развитие гемической гипоксии. Снижения концентрации компонентов свертывающей системы крови возникает при кровопотере $\geq 60 \%$ ОЦК, что приводит к истощению системы гемостаза и развитию ДВС - синдрома. Снижение уровня тромбоцитов до 80 х 109/л наблюдается при кровопотере 80 - 85\% ОЦК. Данная ситуация приводит к возникновению спонтанных кровотечений, и усугублению состояния родильницы. Вышеуказанные изменения требуют многокомпонентную коррекцию. Переливание крови проводили при наличии клинически и лабораторно доказанного снижения гемоглобина, при концентрации ниже 70г/л. Свежезамороженная плазма переливалась всем, так как лабораторно выявляласькоагулопатия, при продолжающихся кровотечениях. Перевязка, лигирование, пережатие кровеносных сосудов включали поэтапную, ступенчатую деваскуляризацию матки, то есть, двустороннее лигирование маточной артерии - О'Лири, были выполнены швы по Б-Линчу, из-за тяжелого послеродового кровотечения (ПРК). Перевязка, лигирование, пережатие кровеносных сосудов были осуществлены кетгутом №6. Во всех случаях был положительным тест эффективности Б-Линча. Гистерэктомия в объеме экстирпация матки с маточными трубами произведена после вагинальных самопроизвольных 2 родов, в затылочном предлежании, в сроке 38 недель беременности после предшествующего кесарево сечение. В родах диагностирован дисстресс плода, потребовалась эпизиотомия для ускорения родов. В раннем послеродовом периоде возникло атоническое кровотечение, потребовавшееручного обследования полости матки. 
Диагностирована постгеморрагическая анемия тяжелой степени. Проведена экстренная лапаротомия. Операция О*Лири и Б-Линча, и припродолжающиемся кровотечении - экстирпация матки с маточными трубами. Кровопотеря составила 2800,0мл,потребовавшая гемотрансфузию, плазмотрансфузию.Послеродовой период протекал без осложнений у 8 из 9 пациенток (88,9 процента). Одна первородящая переведена в Национальный Научный Центр онкологиии трансплантологии на 2 сутки, по поводу преренальнойострой почечной недостаточности 3 степени. Симптоматическая ренальная гипертензия 3 степени. ДВС -синдром. Тромбоцитопения потребления умеренной степени. Анемия сложного генеза (хроническая железнодефицитная и острая постгеморрагическая анемия). Двое родильницв удовлетворительном состояние из - за недоношенного ребенка переведены на 2 этап выхаживания в Национальный Научный Центр материнства и детства.

Среди обследованных, одна повторно забеременела и благополучно родила в доношенном сроке беременности. Другие находятся под наблюдением. Проведена работа по планированию семьи.
Проведенный анализ выявил, что в родильном отделении Акмолинской областной больницы №2 частота акушерских кровотечений снизилась от 4,1\% до 2,3\%(в 1,8 раза) по сравнению с периодом до применения гемостатических швов на матку. Качественно изменилось отношение к удалению органа - матке. Ранее часто проводилась гистерэктомия(23,5-18,8\%), тогда как с внедрением клинического протокола «Акушерские кровотечения» и освоением техники гемостатических швов на матку при акушерских кровотечениях -гистерэктомия снижена в 2 раза.

Таким образом, своевременно проведенные и технически правильно наложенные гемостатические швы на матку являются эффективными методами,позволяющие сохранить орган и последующим репродуктивную функцию у женщин перенесших МАК. Однако, эти случаитребуют дальнейшего исследования по вопросам восстановления менструальной, сексуальной функции и влияния на соматическое состояние.

\section{Литература}

1. Brace V, Penney G, Hall M. Quantifying severe maternal morbidity: a Scottish population study. BJOG. 2004;111:481-4.

2. V.I. Kulakov, V.N. Serov, A.M. Abubakirova, E.A. Chernukha, I.I. Baranov, T.A. Fedorov. Anesthesia and resuscitation in obstetrics and gynecology. "The Triad- $X^{\prime \prime}: 2000 ; 384$

3. Nizard J, Barrinque L, Frydman R, Fernandez H. Fertility and pregnancy outcomes following hypogastric artery ligation for severe post-partum hemorrhage. Hum Reprod. 2003;(18): 844-8.

4. Sentilhes, Trichot C, Resch B, Sergent F, Roman H, Marpeau L, et al. Fertility and pregnancy outcomes following uterine devascularization for postpartum haemorrhage. Hum Reprod.2008;(23):1087-92. 